\title{
Analisis Kandungan Sulfur pada Air Panas di Kaki Gunung Desa Sedoa Kecamatan Lore Utara Kabupaten Poso
}

\author{
Analysis of Sulfur Content in the Hot Springs at the Foot of the Mountain in Sedoa \\ Village North Lore District Poso Regency
}

\author{
M. Pogoa*, Tahril \\ Jurusan Pendidikan MIPA, Fakultas Keguruan dan Ilmu Pendidikan Universitas Tadulako \\ *e-mail: memeykristinapogoa@gmail.com
}

\begin{tabular}{l}
\hline Article Info \\
\hline Article History: \\
Received: 12 October 2021 \\
Accepted: 31 October 2021 \\
Published: 3 November 2021 \\
Keywords: \\
Hot springs, \\
sulfur, \\
gravimetry \\
\end{tabular}

\begin{abstract}
Research on the Sulfur Content Analysis in the Hot Springs at the Foot of the mountain in Sedoa Village, North Lore District, Poso Regency has been conducted. The purpose of this study was to determine the sulfur content in the hot springs at the foot of the mountain in Sedoa Village, North Lore District, Poso Regency. The method used is the Gravimetric method. Hot water samples were taken in the morning and allowed to stand for 3 hours, 1 day, 2 days, and 3 days with 3 different sampling points. Point $A$ is hot water consumed by the community, points $B$ and $C$ are hot water used by the community for bathing and washing. The results showed that the sulfur content of sample $A$ for 3 hours was $9 \mathrm{mg} / \mathrm{L}$, sample $B$ was $4.5 \mathrm{mh} / \mathrm{L}$, sample $C$ was $4.5 \mathrm{mg} / \mathrm{L}$. For 1 day, sample A was $4.5 \mathrm{mg} / \mathrm{L}$, sample $B$ was $4.5 \mathrm{mg} / \mathrm{L}$, sample $C$ was $4.5 \mathrm{mg} / \mathrm{L}$. For 2 days, sample A was $4.5 \mathrm{mg} / \mathrm{L}$, sample $B$ was $4.5 \mathrm{mg} / \mathrm{L}$, sample $C$ was $4.5 \mathrm{mg} / \mathrm{L}$. For 3 days, sample A was $4.5 \mathrm{mg} / \mathrm{L}$, sample $B$ was $4.5 \mathrm{mg} / \mathrm{L}$, sample $C$ was $4.5 \mathrm{mg} / \mathrm{L}$. Sulfur content in the hot springs in Sedoa Village ranges from 4.5 $m g / L-9 m g / L$. This level is far below the standard sulfur content, which is $<400 \mathrm{mg} / \mathrm{L}$.
\end{abstract}

\section{PENDAHULUAN}

Air merupakan sumber daya alam yang diperlukan untuk hajat hidup orang banyak, bahkan oleh semua mahluk hidup. Oleh karena itu, sumber daya air harus dilindungi agar tetap dapat dimanfaatkan dengan baik oleh manusia serta mahluk hidup yang lain. Air juga merupakan pelarut yang sangat baik bagi banyak bahan, sehingga air merupakan transpor utama bagi zat-zat makanan dan produk buangan atau sampah yang dihasilkan proses kehidupan. Oleh karena itu air yang ada di bumi tidak pernah dalam keadaan murni, tetapi selalu ada senyawa atau mineral lain yang terdapat di dalamnya. Meskipun demikian tidak berarti bahwa semua perairan di bumi ini telah tercemar contohnya mata air yang berasal dari daerah pegunungan [1].

Mata air adalah sumber air yang muncul dengan sendirinya ke permukaan dari dalam tanah. Sumber alirannya berasal dari air tanah yang mengalami patahan sehingga muncul ke permukaan. Aliran ini dapat bersumber dari air tanah dangkal maupun dari air tanah dalam. Mata air yang berasal dari air tanah dalam, hampir tidak terpengaruh oleh musim dan kualitas atau kuantitasnya sama dengan keadaan air tanah itu sendiri [2]. Mata air atau air tanah adalah air yang berada di dalam tanah, untuk memperolehnya dengan cara menggali atau dibor atau secara alamiah keluar ke permukaan tanah sebagai mata air, sebagian kecil mata air yang keluar ke permukaan tanah suhunya mencapai di atas $37^{\circ} \mathrm{C}$ atau lebih yang disebut sebagai mata air panas [3].

Mata air panas yang muncul ke permukaan mengindikasikan bahwa adanya suatu sistem panas bumi yang terbentuk di bawah permukaan yang diakibatkan oleh adanya aktivitas geologi, seperti vulkanisme dan tektonisme yang kemudian mengakibatkan air dibawah permukaan mengalami pemanasan, kemudian muncul di permukaan sebagai mata air panas [4]. Mata air panas mengandung berbagai macam mineral seperti Natrium, Litium, Iodium, Besi, Fosfat, Kalium, Nitrat, Kalsium, Magnesium, Klor, Bikarbonat, dan juga Sulfur [5].

Sulfur adalah senyawa multiaktif non-logam dan banyak terdapat di alam, terutama di daerah sekitar gunung merapi. Bentuk asli sulfur adalah kristal padat berwarna kuning, 
namun keberadaannya di alam dapat berupa elemen murni atau sebagai sulfida dan mineral sulfat [6].

Sulfur adalah unsur kimia dalam tabel periodik yang memiliki lambang $\mathrm{S}$ dan nomor atom 16 . Bentuknya adalah non-metal yang tak berasa, tak berbau dan multivalen. Sulfur memang dapat membunuh kuman atau bakteri tertentu yang menyerang kulit. Akan tetapi tidak semua penyakit kulit bisa disembuhkan hanya dengan berendam di pemandian air sulfur [7]. Sulfur adalah mineral alami dekat dengan sumber air panas dan kawah gunung berapi, berbau seperti "telur busuk". Sulfur telah digunakan sebagai pengobatan sejak zaman kuno, dan ini terkandung dalam setiap sel dalam tubuh. Unsur sulfur boleh didapati berdekatan dengan mata air panas [8].

Di Provinsi Sulawesi Tengah Kabupaten Poso tepatnya di Desa Sedoa terdapat mata air panas yang berasal dari pegunungan dan dijadikan sebagai tempat permandian. Air tersebut biasanya digunakan warga setempat untuk kebutuhan sehari-hari seperti memasak. Air tersebut memiliki bau seperti telur busuk dimana bau ini merupakan cirri khas dari sulfur. PERMENKES RI [9] telah menetapkan standar baku sulfur pada air bersih yaitu $<400 \mathrm{mg} / \mathrm{L}$.

Tujuan dari penelitian ini yaitu untuk menganalisis kadar sulfur pada air panas di kaki gunung Desa Sedoa Kecamatan Lore Utara Kabupaten Poso. Permandian air panas Desa Sedoa disajikan dalam gambar 1.

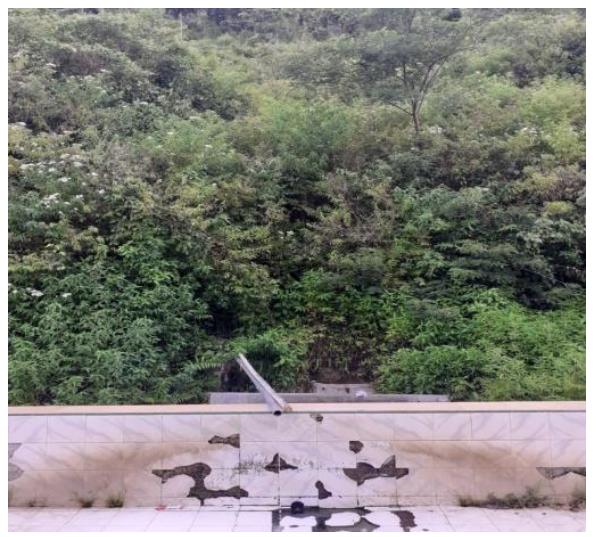

Gambar 1. Permandian Air Panas Desa Sedoa

\section{METODE}

Penelitian ini dilaksanakan di Laboratorium Kimia Fakultas Keguruan dan Ilmu Pendidikan Universitas Tadulako, Palu Sulawesi Tengah.

Alat yang digunakan dalam penelitian ini adalah gelas kimia $250 \mathrm{~mL}$, gelas kimia $400 \mathrm{~mL}$, batang pengaduk, kompor listrik, kertas saring whatman no 42, cawan gooch no 4, oven, desikator, neraca analitik, gelas ukur $100 \mathrm{~mL}$. Bahan yang digunakan adalah $\mathrm{HCl} 37 \%, \mathrm{BaCl}_{2} 10 \%$, akuades, air panas yang diambil dari 3 titik yaitu titik $\mathrm{A}$ air panas yang dikonsumsi, titik $\mathrm{B}$ dan $\mathrm{C}$ air panas yang digunakan untuk mandi dan mencuci. Sampel air panas masing-masing diukur sebanyak $400 \mathrm{~mL}$ dan dimasukkan kedalam gelas kimia yang telah diberi label $\mathrm{A}, \mathrm{B}$, dan $\mathrm{C}$ lalu ditambahkan larutan $\mathrm{HCl}$
$37 \%$ masing-masing sebanyak $15 \mathrm{~mL}$ kemudian dipanaskan sampai larutan menjadi $50 \mathrm{~mL}$ dan disaring. Akuades ditambahkan ke dalam masing masing filtrat sebanyak 200 $\mathrm{mL}$ dan dipanaskan (tidak sampai mendidih). Larutan $\mathrm{BaCl}_{2}$ $10 \%$ ditambahkan ke dalam masing-masing larutan sebanyak $25 \mathrm{~mL}$ sambil diaduk kemudian masing-masing larutan dipanaskan selama 1 jam sampai terbentuk endapan putih dan disaring saat masi panas menggunakan cawan gooch yang sudah diketahui massanya. Residu hasil penyaringan dimasukkan dalam oven pada suhu $230^{\circ} \mathrm{C}$ selama 2 jam kemudian dimasuskkan dalam desikator dan ditimbang secara berulang hingga diperoleh massa konstan [10]. Reaksi yang terjadi:

$$
\mathrm{H}_{2} \mathrm{~S}+\mathrm{BaCl}_{2} \longrightarrow 2 \mathrm{HCl}+\mathrm{BaS}
$$

\section{Analisis Data}

Aanalisa data dilakukan berdasarkan hasil yang diperoleh dari pengujian sampel dengan metode pengendapan gravimetri. Dalam prosedur gravimetri yang lazim, endapan BaS di timbang, dan darinya sulfur (S) dalam sampel dapat dihitung. Maka rumus yang digunakan adalah

$$
\text { Kadar Sulfur } S=\frac{\operatorname{ArS}}{M r B a S} \mathrm{X} \text { massa BaS }
$$

\section{HASIL DAN PEMBAHASAN}

Hasil penelitian yang di peroleh dari analisis kandungan sulfur (S) pendiaman 3 jam dari lokasi, pendiaman 1 hari, pendiaman 2 hari, dan pendiaman 3 hari dengan metode gravimetri merupakan hasil data mengenai analisis kandungan sulfur (S) yang diambil dari air panas di kaki gunung desa Sedoa Kecamatan Lore Utara Kabupaten Poso. Data hasil analisis kandungan sulfur (S) disajikan dalam tabel 1 dan gambar 2

Tabel 1. Kadar sulfur (S) dalam air panas Desa Sedoa

\begin{tabular}{ccccc}
\hline \multirow{2}{*}{ Sampel } & \multicolumn{4}{c}{ Kadar Sulfur (S) } \\
\cline { 2 - 5 } & $\begin{array}{c}\text { Pendia } \\
\text { man 3 } \\
\text { jam } \\
(\mathbf{m g} / \mathbf{L})\end{array}$ & $\begin{array}{c}\text { Pendiam } \\
\text { an 1 hari } \\
(\mathbf{m g} / \mathbf{L})\end{array}$ & $\begin{array}{c}\text { Pendiam } \\
\text { an 2 hari } \\
(\mathbf{m g} / \mathbf{L})\end{array}$ & $\begin{array}{c}\text { Pendiam } \\
\text { an 3 hari } \\
(\mathbf{m g} / \mathbf{L})\end{array}$ \\
\hline A & 9 & 4,5 & 4,5 & 4,5 \\
B & 4,5 & 4,5 & 4,5 & 4,5 \\
C & 4,5 & 4,5 & 4,5 & 4,5 \\
\hline
\end{tabular}




\section{Kandungan Sulfur (S)}

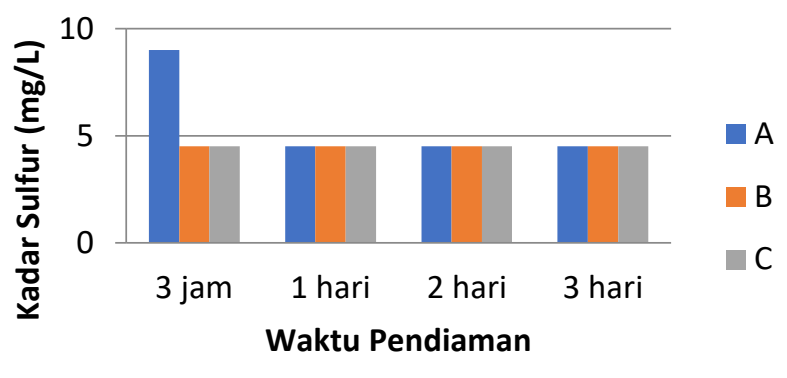

Gambar 2. Grafik Kadar Sulfur (S) dalam Air Panas Desa Sedoa

\section{Pembahasan}

Sebelum dianalisis pertama-tama sampel air diambil dengan menggunakan botol aqua berukuran $600 \mathrm{ml}$ yang sudah di bugkus dengan lakban berwarna hitam, pembungkusan botol bertujuan agar air terhindar dari pengaruh cahaya atau temperatur yang dapat mengakibatkan rusaknya sampel air [12]. Pengambilan sampel diambil dari tiga titik, titik A merupakan air panas yang dikonsumsi masyarakat, titik $\mathrm{B}$ dan $\mathrm{C}$ merupakan air panas yang digunakan masyarakat untuk mandi dan mencuci. Suhu dari sampel dititik A 380C sedangkan dititik B dan C yaitu 370C. Pengambilan sampel dilakukan pada pagi hari. Selanjutnnya sampel dibawa ke laboratorium untuk dianalisis menggunakan metode gravimetri.

Sulfur $(\mathrm{S})$ atau belerang adalah unsur kimia di dalam sistim periodik yang mempunyai simbol $\mathrm{S}$ dan nomor atom 16 . Sulfur (S) bukan logam multivalen yang berlimpah, tanpa rasa dan tanpa bau. Sulfur (S) dalam bentuk aslinya, adalah satu kristal padat yang berwarna kuning. Sulfur (S) ditemukan di alam dalam bentuk unsur murni atau dalam bentuk mineral sulfida atau sulfat. Sulfur (S) merupakan unsur penting untuk kehidupan. Sulfur (S) adalah mineral alami dekat dengan sumber air panas dan kawah gunung berapi, Unsur sulfur (S) boleh didapati berdekatan dengan mata air panas [13].

Sulfur (S) sangat luas penggunaanya dan masih merupakan salah satu bahan terapi yang terbaik dan paling luas digunakan dalam berbagai gangguan keratin kulit. Di dalam kosmetik, sulfur (S) koloidal digunakan dalam pengobatan jerawat, ketombe. Pengobatan jerawat menggunakan sulfur (S) merupakan cara tradisional yang sudah ada sejak dulu. Melihat fakta manfaat yang cukup baik bagi kulit tersebut banyak ilmuwan yang melakukan observasi dan melakukan penelitian dan mengembangkan produk kosmetik yang mengandung sulfur (S) salah satunya adalah sabun sulfur (S). Walaupun memiliki manfaat bagi kulit, akan tetapi penggunaan sulfur (S) dalam takaran berlebihan juga sangat tidak disarankan [14].

Perlakuan pada analisis kadar sulfur (S) yaitu sampel air panas diambil sebanyak $400 \mathrm{ml}$ kemudian dianalisis dengan menggunakan metode gravimetri. Dalam penelitian ini larutan yang digunakan sebagai pereaksi yaitu larutan $\mathrm{BaCl} 2$. Tujuan penambahan $\mathrm{BaCl} 2$ yaitu sulfur $(\mathrm{S})$ dapat diikat oleh ion $\mathrm{Ba} 2+$ sehingga membentuk endapan putih yaitu BaS, seperti pada reaksi berikut:

$$
\mathrm{BaCl}_{2}+\mathrm{H}_{2} \mathrm{~S} \longrightarrow 2 \mathrm{HCl}+\mathrm{BaS}
$$

Berdasarkan hasil pengamatan dan perhitungan maka diperoleh kadar sulfur (S) pada sampel seperti pada tabel 1 dan gambar 2. Dari hasil tersebut dapat dilihat bahwa kandungan sulfur (S) pada pendiaman 3 jam yang paling banyak, yaitu sebesar $9 \mathrm{mg} / \mathrm{L}$ terdapat pada lokasi panggambilan dititik A yang merupakan sumber utama air panas. Berbeda halnya dengan lokasi pengambilan dititik B dan C. adapun kadar sulfur pada dua lokasi tersebut mengandung lebih sedikit yaitu 4,5 mg/L. Sedangkan kandungan sulfur (S) pada pendiaman 1 hari, 2 hari, dan 3 hari menunjukan bahwa tidak terjadi perubahan yang signifikan antar kadar sulfur (S) dalam sampel yang didiamkan yaitu sebesar 4,5 $\mathrm{mg} / \mathrm{L}$. perbedaan kadar sulfur (S) tersebut disebabkan oleh lokasi A merupakan sumber mata air panas sedangkan lokasi B dan $\mathrm{C}$ hanya menampung air yang berasal dari sumber air panas. Hal ini juga disebabkan oleh $\mathrm{pH}$ dan suhu, nilai $\mathrm{pH}$ air panas pada lokasi A lebih rendah dari air panas pada lokasi B dan C. Sekitar 99\% sulfur (S) terdapat dalam bentuk H2S pada $\mathrm{pH} 5$, Kondisi ini menimbulkan tekanan parsial Sulfur (S) bersifat mudah larut, dan menimbulkan bau seperti telur busuk [13]. Kondisi fisik air panas di Desa Sedoa berbau seperti telur busuk. Suhu air pada lokasi A lebih tinggi dari pada suhu air pada lokasi B dan C, dimana kenaikan suhu mempengaruhi komposisi kimia air tanah yang pada umumnya kelarutan akan makin besar [15].

Standar baku mutu kandungan sulfur (S) didalam air menurut peraturan Menteri Kesehatan Republik Indonesia nomor 492/menkes/PER/IV/2010 tentang persyaratan kualitas air bersih yaitu < $400 \mathrm{mg} / \mathrm{L}$. Kadar sulfur (S) yang diperoleh dalam air panas di Desa Sedoa jauh di bawah standar baku yang telah ditetapkan. Apabila kadar sulfur (S) pada air melebihi ambang batas, maka akan mengakibatkan terjadinya gangguan pada sistem pencernaan dan gangguan iritasi kulit [16]. Secara umum kandungan sulfur pada air panas di Desa Sedoa masi berada dalam ambang batas yang diperbolehkan untuk air bersih. Namun, perlu waspada karena air panas tidak hanya mengandung sulfur (S), masi ada beberapa kandungan kimia yang harus diketahui agar air tersebut memenuhi standar baku air bersih dan layak untuk dikonsumsi.

\section{KESIMPULAN}

Kadar sulfur (S) pada air panas yang terdapat di Desa Sedoa yaitu berkisar antara $4,5 \mathrm{mg} / \mathrm{L}-9 \mathrm{mg} / \mathrm{L}$, kadar tersebut jauh dibawah standar baku sulfur (S) yang telah di tetapkan oleh PERMENKES RI yaitu $<400 \mathrm{mg} / \mathrm{L}$.

\section{UCAPAN TERIMA KASIH}

Ucapan terima kasih penulis berikan kepada laboran beserta staf Laboratorium Kimia Fakultas Keguruan dan Ilmu 
Pendidikan Universitas Tadulako yang banyak membantu penulis dalam menyelesaikan penelitian.

\section{REFERENSI}

[1] H. Efendi, "Telaah kualitas air bagi pengelolaan sumber daya dan lingkungan perairan". Yogyakarta. Kanisius. 2003.

[2] F. Unaya, "Sebaran Mata Air Panas di Kabupaten Serang". FKIP. Universitas Indonesia. Depok. 2012.

[3] I. W. Arthana. "Studi Kualitas Air Beberapa Mata Air di Sekitar Bedugul Bali". Program Studi Magister Ilmu Lingkungan Universitas Udayana, Denpasar. 2009.

[4] Herman. "Potensi panas bumi". Direktorat Inventarisasi Sumber Daya Mineral. 2005.

[5] E. Kadarsetia, S. Primulyana, P. Sitinjak \& SU. Boyson "Karakteristik Kimiawi Air Danau Kawah Gunung Api Kelud, Jawa Timur Pasca Letusan Tahun 1990”. Jurnal Geologi Indonesia 1(4), pp.185-192. 2006.

[6] A. Komala, "Paparan Uap Belerang Sebagai Faktor Risiko Terjadinya Erosi Gigi”. Fakultas Kedokteran Universitas Kedokteran. Semarang. 2006.

[7] Herman \& S. Soeleman. "Analisis Kandungan Sulfur yang Terdapat Pada Sumber Air Panas Makula Tana Toraja”. Jurnal Media Analisis, 2(4). 2015.

[8] Hepiyansori. "Kadar Sulfur Pada Sumber Air panas Alamai Suban Di Curup Kabupaten Rejang Lebong Menurut Siklus Musim Berbeda". Journal ilmiah Pharmacy, 2(3). 2016.

[9] PERMENKES, "Peraturan Mentri Kesehatan No. 492 Tahun 2010 Tentang Syarat Mutu Kualitas Air Bersih", Jakarta. 2010.

[10] M. Istiqomah. "Verifikasi Metode Pengujian Kadar P2o5 Citrate Soluble Secara Spektrofotometri Uv-Visibel dan Sulfur Secara Gravimetri pada Pupuk Sp-36 Di Pt Petrokimia Gresik". Universitas Islam Indonesia. Yogyakarta. 2019.

[11] R. A. Day. and A. L. Underwood, "Analisis kimia Kuantitatif”. Edisi keenam. Jakarta. Erlangga.2002.

[12] Nafiadi, N. Majid. "Pencemaran Air Sungai Garuda Akibat Pembuangan Limbah Industri Tahu Di Kecamatan Sragen Kabupaten Sragen”. Universitas Muhammadiyah Surakarta. 2013.

[13] M. E. Wibowo. "Pengaruh Kadar Sulfur pada Air Sumur Terhadap Erosi Gigi pada Masyarakat di
Kecamatan Asembagus Kabupaten Situbondo". Fakultas Kedoteran Gigi. Universitas Jember. Jember. 2012.

[14] S. Rahayu, "Mengoptimalkan Aspek Literasi dalam Pembelajaran Kimia Abad 21". Jurusan Kimia FMIPA. Universitas Negri Malang. Malang. 2017.

[15] I. Rizkiyah. "Identifikasi Kandungan Mineral Sulfat $\left(\mathrm{SO} 42^{-}\right)$, Klorida $\left(\mathrm{Cl}^{-}\right)$, Magnesium $(\mathrm{Mg})$ dan Kalsium (Ca) pada Air Panas Obyek Wisata Pemandian Air Panas Guci, Tegal". Fakultas Ilmu Tarbiyah dan Keguruan. IAIN Walisongo, Semarang. 2013.

[16] H. Rumahorbo. "Analisis Kadar Sulfur pada Danau Linting Desa Sibunga-bunga Hilir Kecamatan Sinempah Tanjung Muda Hulu dengan Metode Turbidimetri”. Departemen Kimia Fakultas MIPA Universitas Sumatera Utara, Medan. 2017. 